\title{
Dynamic Optimization for IPS2 Resource Allocation Based on Improved Fuzzy Multiple Linear Regression
}

\author{
Maokuan Zheng, Xinguo Ming, and Guoming Li \\ School of Mechanical Engineering, Shanghai Jiao Tong University, Shanghai, China \\ Correspondence should be addressed to Maokuan Zheng; zhengmaokuan@163.com
}

Received 5 October 2016; Accepted 12 February 2017; Published 27 February 2017

Academic Editor: Ibrahim Zeid

Copyright ( 2017 Maokuan Zheng et al. This is an open access article distributed under the Creative Commons Attribution License, which permits unrestricted use, distribution, and reproduction in any medium, provided the original work is properly cited.

\begin{abstract}
The study mainly focuses on resource allocation optimization for industrial product-service systems (IPS2). The development of IPS2 leads to sustainable economy by introducing cooperative mechanisms apart from commodity transaction. The randomness and fluctuation of service requests from customers lead to the volatility of IPS2 resource utilization ratio. Three basic rules for resource allocation optimization are put forward to improve system operation efficiency and cut unnecessary costs. An approach based on fuzzy multiple linear regression (FMLR) is developed, which integrates the strength and concision of multiple linear regression in data fitting and factor analysis and the merit of fuzzy theory in dealing with uncertain or vague problems, which helps reduce those costs caused by unnecessary resource transfer. The iteration mechanism is introduced in the FMLR algorithm to improve forecasting accuracy. A case study of human resource allocation optimization in construction machinery industry is implemented to test and verify the proposed model.
\end{abstract}

\section{Introduction}

The development of industrial product-service systems (IPS2) has greatly transformed business models from product economy to service economy [1]. With the fast development of intelligent manufacturing technologies, homogenization of products in function, quality, and capability has intensified competition in technical innovation. Based on this situation, more companies are trying to seek new opportunities and differentiated competition in business mode innovation by offering personalized and ultraexperienced services with high quality, fast response, and good customer experience.

Most of the existing researches about IPS2 mainly focus on the strategic level solutions, including innovative business models [2] or value cocreation mechanisms [3]. Details of research review on IPS2 can be found in Section 2.1. However, with the business model evolving, more and more companies realize that increasing service tasks and disorganized service operation have brought great pressure to their business profitability and expansion. Different from average cost reduction in mass production, resource demand and costs for service providing are positively correlated with the quantity and distribution range of customers. Without effective management, the increasing operation and maintenance costs in an IPS2, resulting from more and more fixed assets and human resource along with the expanding of service network, will become a heavy burden for those service providers. So, waste elimination and efficiency improvement in resource operation have become the key to keep lasting competitiveness for those IPS2 providers.

For better understanding of the problem discussed in this work, a concept model for a typical modern IPS2 network is developed as depicted in Figure 1. The model is abstracted to three procedures. Procedure A is the acquiring of customer demands. Procedure B is the generation and configuration of service tasks among the network. Procedure $\mathrm{C}$ is the allocation of related service resources. In procedure A, different external factors may cause the uncertainty of customer needs and randomness of service requests. This leads to the volatility of service orders and tasks in Procedure B. Then the effect passes on to Procedure $\mathrm{C}$, which finally leads to the fluctuation of resource utilization rate because of different service flow and resource demand for different service tasks. Resources may be excessive redundancy at this moment, 


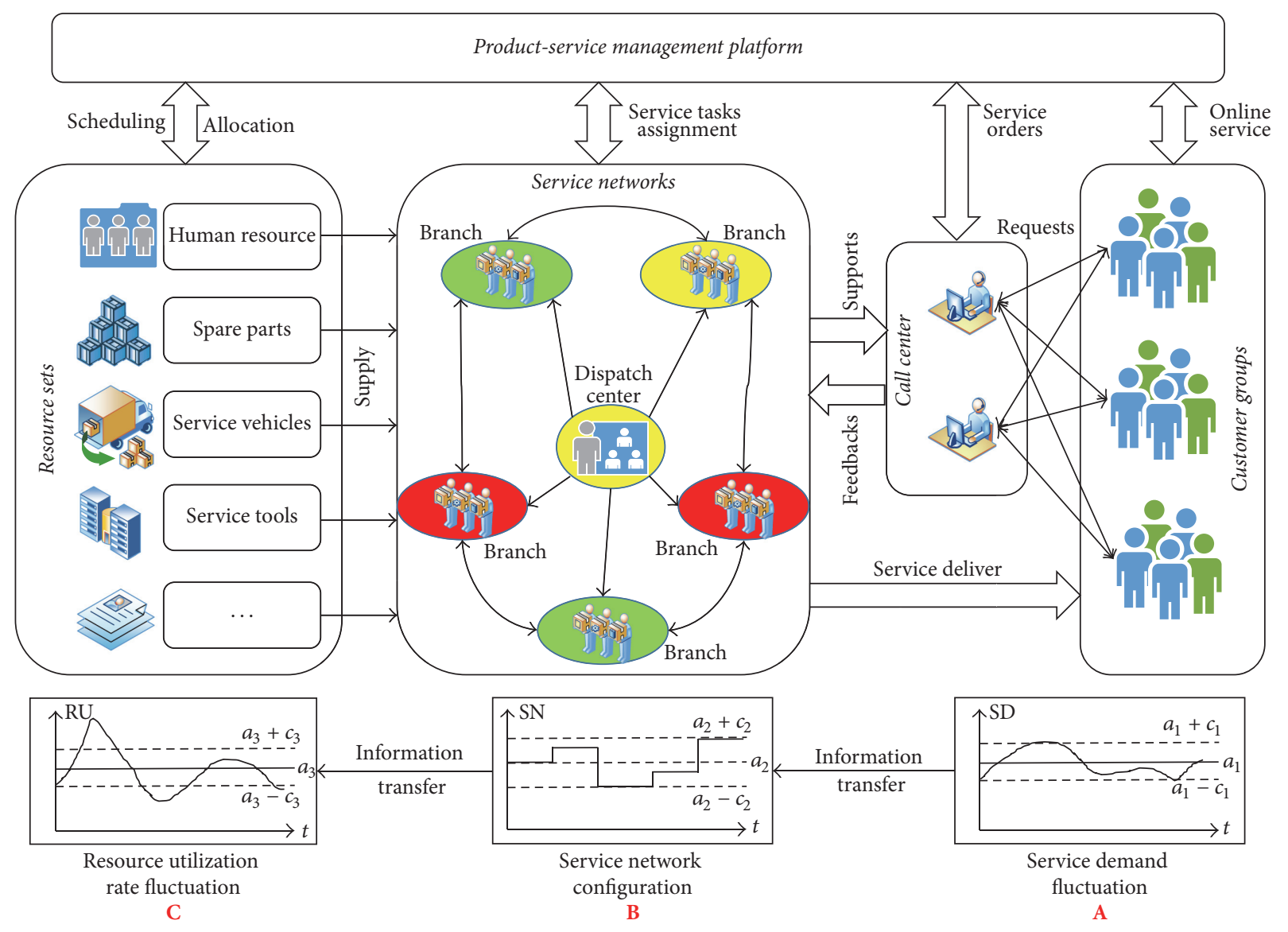

FIGURE 1: IPS2 network and the phenomenon of resource utilization ratio fluctuation.

while extremely deficient at the next moment. The whole process causes the mismatch of real-time service capabilities and random customer demands [4]. So here comes the need for a flexible and effective optimization method for service resources allocation depending on dynamic situations. As most of the services are delivered by service engineers with a lot of direct interactions with customers, service engineers are significant parts of IPS2 resource pool. Reasonable arrangement and scheduling of service engineer tasks can significantly improve service efficiency. This work tries to offer a possible solution at the operational level for balanced IPS2 resource allocation optimization, especially for human resource.

Based on analysis above about backgrounds and industrial needs, the rest of the work will be organized as follows. A literature review about existing related work, including IPS2, IPS2 resources allocation methods, and FMLR, is presented in Section 2. Then, a method based on fuzzy multiple linear regression for IPS2 resource allocation optimization is developed in Section 3. Three basic rules and the technology roadmap of the research are put forward in Section 3.1. The detailed modelling and solving processes are presented in Sections 3.2 to 3.4. A case study about human resource allocation optimization in construction machinery industry is implemented for testing and verification of the proposed approach in Section 4. Finally, the results and conclusions are discussed and summarized in Section 5 for further improvement.

\section{Related Work}

2.1. Industrial Product-Service Systems (IPS2). The concept of industrial product-service systems (IPS2) is developed from product-service systems (PSS). PSS was first proposed for minimizing environmental impacts of both production and consumption to pursuit sustainable development through applying different methods of environmental policy [5]. Product-service systems are defined as customer lifecycleoriented combinations of products and services, realized in an extended value creation network [1], comprising a manufacturer as well as suppliers and service partners [6].

Then, PSS theories and applications focusing on industrial areas drew the attention from both industry and academy, leading to the development of IPS2 related research. IPS2 is characterized by the integrated and mutually determined planning, development, provision, and use of product and service shares including its immanent software components in Business-to-Business applications and represents a knowledge-intensive sociotechnical system [7]. According to different business models, IPS2 can be classified into three 
categories, which are product oriented IPS2, use oriented IPS2, and result oriented IPS2 [8, 9]. Aurich et al. [10] introduced a lifecycle management (LCM) framework for IPS2, covering four phases, namely, organizational implementation, planning, design, and realization. Many successful IPS2 cases have revealed the powerful vitality of the business model $[11,12]$. Then some approaches and tools for PSS design were also studied $[13,14]$.

2.2. IPS2 Resource Allocation Optimization. As IPS2 are systems with complex stakeholder interaction, resource demand and allocation are deeply influenced by lots of inner and outer factors. The problem of IPS2 resource allocation optimization is actually to predict resource real demand accurately and balance resource utilization ratio by taking comprehensive conditions into consideration. There are still very few specialized researches about IPS2 resource allocation optimization in academic area. Some existing related researches and proposed theories may inspire us with some new ideas. Meier and Funke [15] discussed characters of resource planning of IPS2 and proposed a heuristic resource planning approach. Schuh et al. [16] studied the structural model of resources in PSS and a prerequisite to portfolio design and planning. Steven and Richter [17] came up with the concept of hierarchical planning for industrial product-service systems. These three researches were all published in the proceedings of the 2 nd CIRP IPS ${ }^{2}$ conference, trying to offer possible solutions from the strategic and concept level without specific application areas and further verifications. There are also some earlier researches from the view of supply chain management. Meier and Völker [18] introduced the typology of service supply chain for IPS2 providing, describing a conceptual extraorganizational structure to manage the delivery during IPS2 lifecycle autonomously. But the research mainly focused on upper reaches of the value chain, considering little about customer needs and market conditions. Furthermore, the conceptual structure was not verified with a specific application case study. Unlike goods producing and supplying, services are produced and delivered at the same time. The randomness of service requests leads to the main challenge for effective resource planning and allocation. Service uncertainties are driven by the poor quality of information flow and unavailable of useful knowledge across a given service network [19]. The research analysed the components of service delivery system and classification of sources of uncertainty based on supply and demand. However, the proposed uncertainty modelling methods were only applied in service cost estimation without more extension. Rese et al. [20] spotted the dynamic features and characters of IPS2 in customer needs and external market environment, which leads to the additional challenge of having to generate sustainable competitive advantages.

2.3. Fuzzy Multiple Linear Regression (FMLR). Linear regression is a widely used method for engineering optimization and trend forecasting [21, 22]. The method got further developed to adapt different scenarios. Fuzzy multiple linear regression was first introduced by Tanaka [23] with the application of fuzzy linear function to a regression analysis in a vague phenomenon. In the usual regression model, deviations between the observed values and the estimated values are supposed to be due to observation errors. Tanaka [23] assumed that these deviations depend on the indefiniteness of the system structure and could be regarded as the fuzziness of system parameters. Thus they are reflected in a fuzzy linear function which represents a vague phenomenon. Then the theory was further applied to various areas for forecasting problems modelling and solving. Abdullah and Zamri [24] developed the road traffic accidents models using threshold levels of fuzzy linear regression. Ramedani et al. [25] adopted the method for global solar radiation prediction in Iran. Atalay et al. [26] studied a hybrid algorithm based on fuzzy linear regression analysis by quadratic programming for standard work time estimation in manufacturing industries.

By the conclusions and applications of existing work, it can be found out that the FMLR method integrates the strength and concision of multiple linear regression in data fitting and factor analysis and the merit of fuzzy theory in dealing with uncertain or vague problems by imitating human decision making processes, which matches the requirements in solving the IPS2 resource allocation optimization problems. Based on that, the model gets further development and application in this work.

\section{IPS2 Resource Allocation Optimization Approach Based on FMLR}

3.1. Basic Rules and Technology Roadmap. Based on the analysis of the concept, characters, and applications about IPS2 in Section 2, three basic rules for directing the design of IPS2 resource allocation optimization approaches are proposed as follows:

(i) Rule 1: resources are connected and shared at the highest degree, which can be represented by the quantity and distribution range of objects served by unit resource.

(ii) Rule 2: minimize the fluctuation of service resource utilization ratio within an acceptable and reasonable range.

(iii) Rule 3: Eliminate those costs caused by unnecessary resource transfer and mobilization to the lowest level.

Rule 1 is applied to control the total resource investment under an acceptable level by using the thought of discrete distribution and integrated management. Rule 2 is used to balance resource utilization ratio in order to enhance service system stability. Rule 3 offers a threshold management method to reach better operating economy.

Based on the three basic rules, the technology roadmap of this work for IPS2 resource allocation optimization is presented in Figure 2. The whole process consists of 4 procedures, which are correlation factors recognition in Procedure A, real resource demand analysis in Procedure B, problem modelling and solving with FMLR method in Procedure C, and service resource allocation optimization according to calculated fuzzy equations by resource rescheduling and transfer in Procedure D. The four procedures will be explained in 


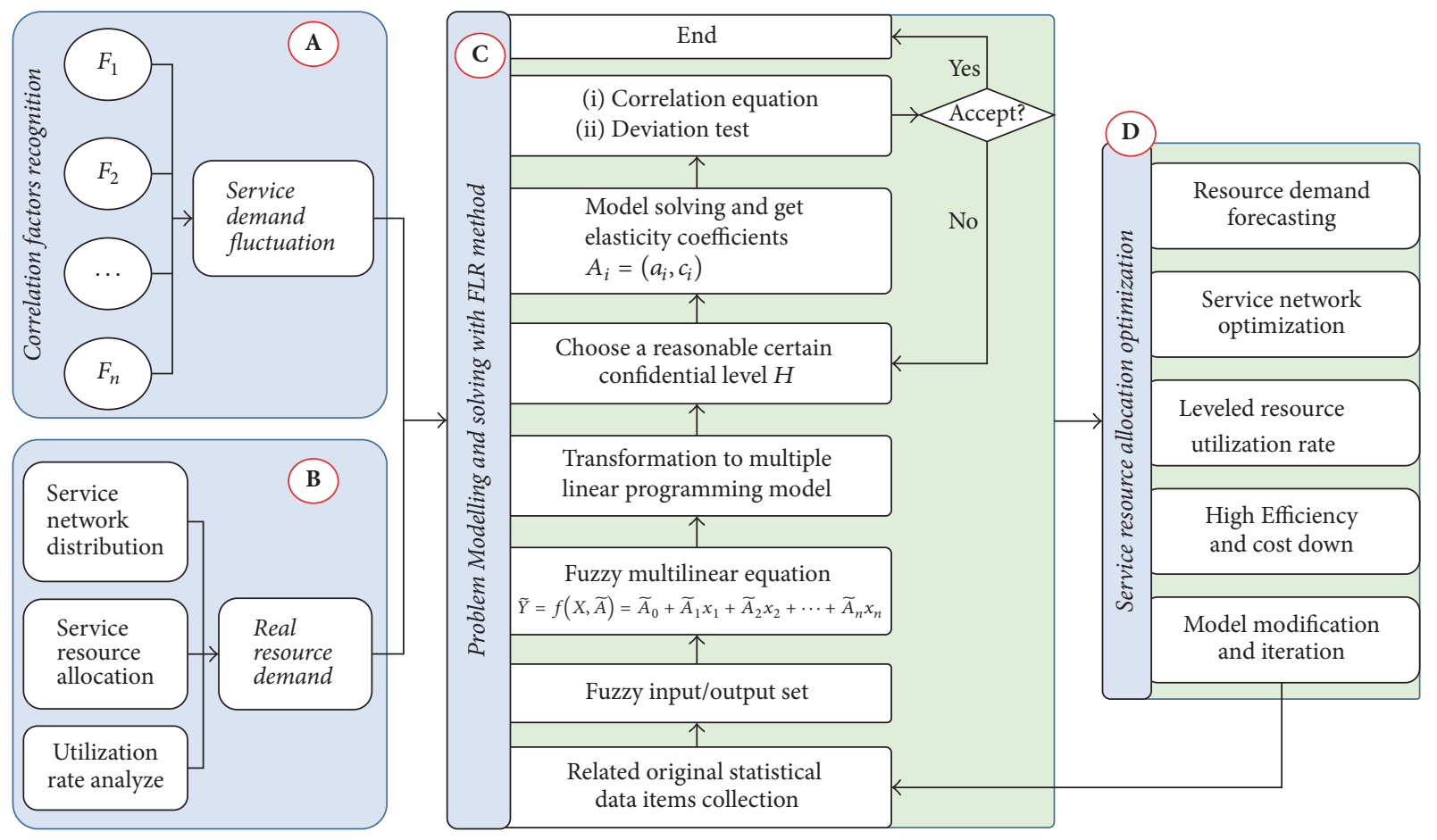

FIGURE 2: Technology roadmap of the proposed method in this work.

detail in Section 3 and applied in Section 4 for practice. The rest of the article is also organized following this main line.

\subsection{Correlation Factors Recognition and Real Resource} Demand Analysis. For better recognition of those correlation factors that influence service demand and resource mutilations rates, a correlation analysis method is used. Factors at the user end do not act on the needs of resources directly, namely, the needs for resources are the result of a complex causal chain. The casual chain is abstracted as a fivelayer model (see Figure 3), including user end, factors for service requests, characters of service requests, characters of resources, and resource end. It is too complicated to figure out specific correlation superposition of every step. What we want to get is the direct functional relationship between service request factors and resources character, by treating forward and afterward relationship with the middle layer of service requests characters as a black box. Factors for service request mainly come from two dimensions, factors of products (e.g., use intensity, use condition, etc.) and factors of users (e.g., use habit, work load, etc.). Resources generally can be classified into four kinds, human resources (e.g., operators), materials, tools, and equipment (e.g., vehicles). Those elements of the two layers can be listed either by expert suggestions or by historical service record statistics according to specific characters of different industries. FMLR method will be applied to solve the black box problem in the following part.

Before that, the volatility of resource utilization ratio $v_{\text {ua }}$ should be defined accurately. Here, another four auxiliary parameters are introduced, including actual resource amount $M_{a}^{t}$, real resource demand $M_{r}^{t}$ resource holding time $T_{h}^{t}$, and standard working time $T_{s}$. According to historical data statistics of $M_{a}^{t}, T_{h}^{t}$, and $T_{s}, M_{r}^{t}=M_{a}^{t} \cdot T_{h}^{t} / T_{s}$. And the real-time volatility of resource utilization ratio $v_{\text {ua }}=$ $T_{h}^{t} / T_{s}$. When $v_{\text {ua }}>1$, resources are overloaded. And when $v_{\text {ua }}<1$, resources are overredundant without effective utilization. Our purpose of following approach is to control and minimize the fluctuation of $v_{\text {ua }}$ within a reasonable range $c$, which can be described as $\left|T_{h}^{t} / T_{s}-1\right| \leq c$ at any time $t$.

\subsection{Problem Modelling and Solving with Fuzzy Multiple Linear Regression Method}

3.3.1. Problem Modelling. Let us consider two sets $X$ and $Y$, where $X$ is an $n$-dimension factor parameter matrix and $Y$ is the output vector of resource allocation parameters. Both $X$ and $Y$ have $m$ groups of observations. At any time $t$, suppose the nonfuzzy observation of input vector $X^{t}$ and output value $y^{t}$ have the correlation of $y^{t}=A \cdot X^{t}$, where $A=\left[A_{0}, A_{1}, \ldots, A_{n}\right]$ is the coefficient set. By introducing fuzzy numbers in coefficient set $A$ and output vector $Y$ for the realistic meaning of reduced resource transfer quantity and costs, the base model can be assumed a fuzzy linear function as follows $[23,26]$ :

$$
\tilde{y}^{t}=f\left(X^{t}, \widetilde{A}\right)=\widetilde{A}_{0}+\widetilde{A}_{1} x_{1}^{t}+\widetilde{A}_{2} x_{2}^{t}+\cdots+\widetilde{A}_{n} x_{n}^{t},
$$

where $X^{t}=\left[x_{1}^{t}, x_{2}^{t}, \ldots, x_{n}^{t}\right]^{T},(t=1,2, \ldots, m)$, is the input vector of factor parameters at time $t$. Define $x_{0}^{t}=1 . \widetilde{A}_{i}(i=$ $1,2, \ldots, n)$ are the fuzzy coefficients in the form of $\left(a_{i}, c_{i}\right)$, where $a_{i}$ is the middle and $c_{i}$ is the spread value. Regression 


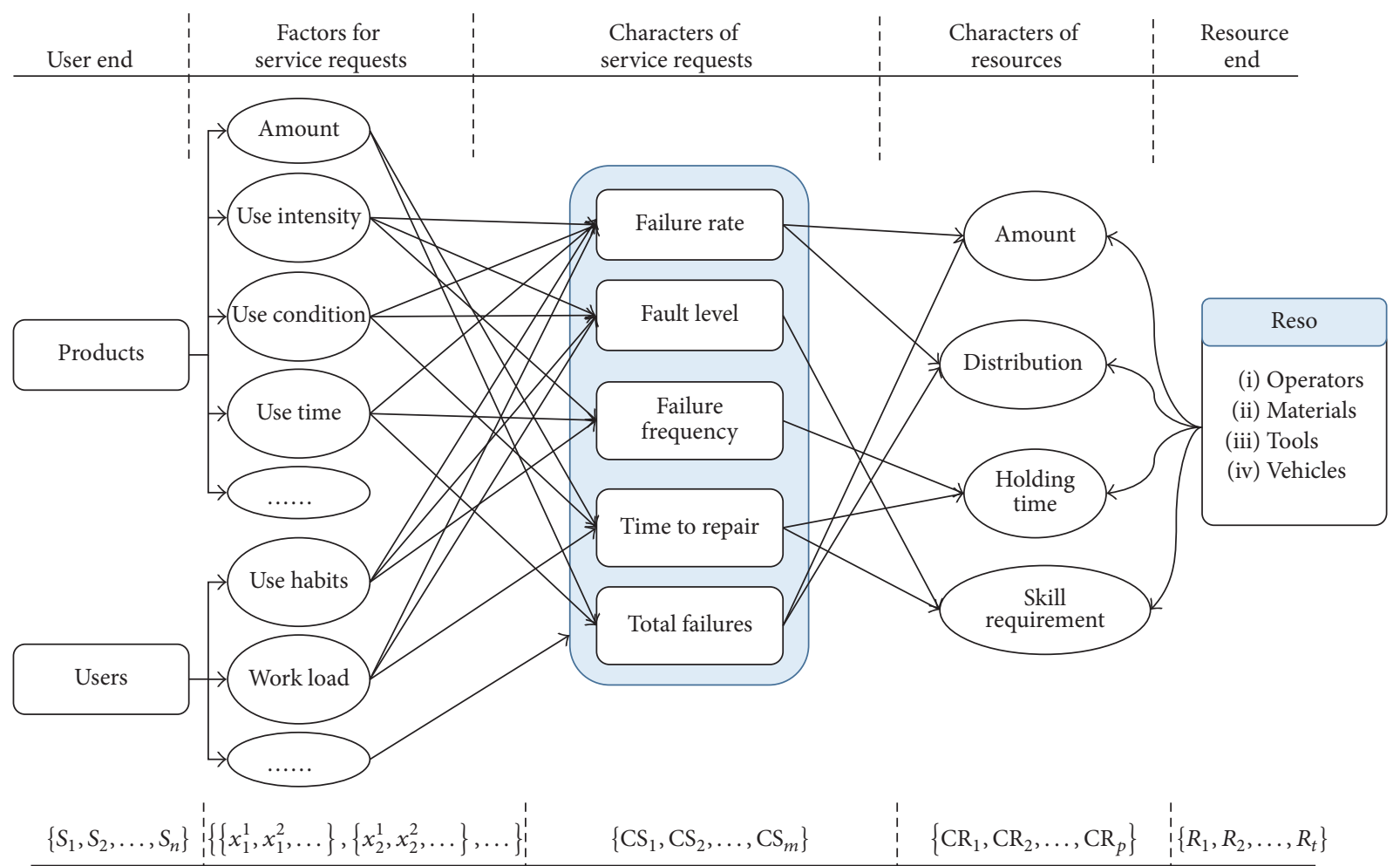

FIGURE 3: Basic reference model for correlation factors recognition.

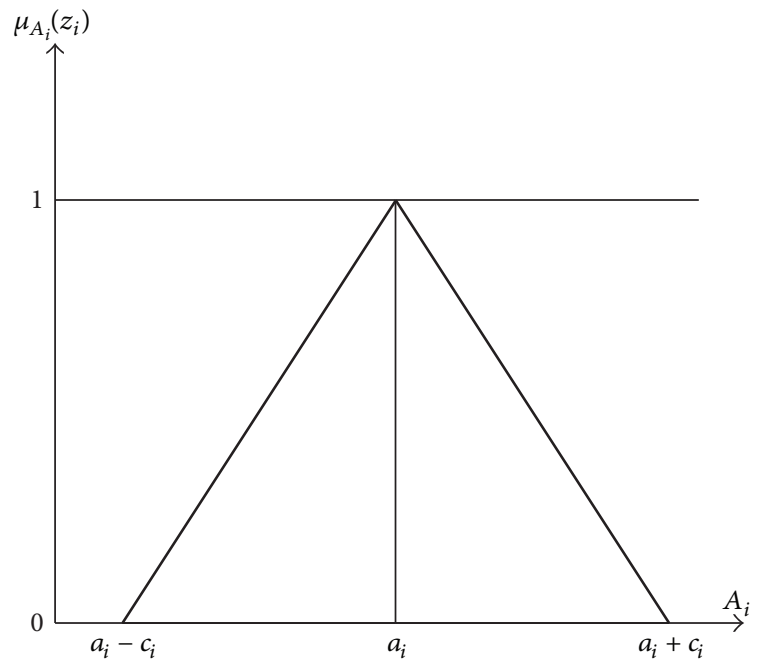

Figure 4: A triangular fuzzy regression coefficient.

coefficients were supposed to be a symmetric triangular fuzzy number and the membership function is shown in Figure 4 and can be formulated as

$$
\mu_{A_{i}}\left(z_{i}\right)= \begin{cases}1-\frac{\left|z_{i}-a_{i}\right|}{c_{i}}, & \left(a_{i}-c_{i}\right) \leq z_{i} \leq\left(a_{i}+c_{i}\right), \\ 0, & \text { otherwise. }\end{cases}
$$

Therefore, formula (1) can be rewritten as

$$
\begin{array}{r}
\tilde{y}^{t}=\left(a_{0}, c_{0}\right)+\left(a_{1}, c_{1}\right) x_{1}^{t}+\cdots+\left(a_{n}, c_{n}\right) x_{n}^{t}, \\
t=1,2, \ldots, m,
\end{array}
$$

where $\tilde{y}^{t},(t=1,2, \ldots, m)$ is the corresponding estimated output interval and has a fuzzy set that is characterized by symmetric triangular membership function $\mu_{\hat{y}^{t}}\left(y^{t}\right)$, with centre $\widetilde{y}^{t}$ and spread $e^{t}$ and $\widetilde{y}^{t}=\left(\bar{y}^{t}, e^{t}\right)$. Membership function $\mu_{\tilde{y}^{t}}\left(y^{t}\right)$ is denoted as follows:

$$
\begin{aligned}
& \mu_{\tilde{y}^{t}}\left(y^{t}\right) \\
& \quad= \begin{cases}1-\frac{\left|y^{t}-\bar{y}^{t}\right|}{e^{t}}, & \left(\bar{y}^{t}-e^{t}\right) \leq y^{t} \leq\left(\bar{y}^{t}+e^{t}\right), \\
0, & \text { otherwise. }\end{cases}
\end{aligned}
$$

The estimated output $\tilde{y}^{t}$ can be obtained by using the extension principle. As $\bar{y}^{t}=X^{T} a$ and $e^{t}=c^{T}|X|$, membership function of fuzzy number $\widetilde{Y}^{t}$ can be stated as

$$
\mu_{\widetilde{y}^{t}}\left(y^{t}\right)= \begin{cases}1-\frac{\left|y^{t}-X^{T} a\right|}{c^{T}|X|}, & X \neq 0, \\ 1, & X=0, Y=0, \\ 0, & X=0, Y \neq 0,\end{cases}
$$


where $c^{T}=\left(c_{0}, c_{1}, \ldots, c_{n}\right), a=\left(a_{0}, a_{1}, \ldots, a_{n}\right)$. The FLRA mentioned above assumes crisp input and output data, while the relation between the input and output data is defined by fuzzy function. The distribution of its parameter is a possibility function. And then, (5) can be rewritten as

$$
\mu_{\tilde{y}^{t}}\left(y^{t}\right)= \begin{cases}1-\frac{\left|y^{t}-\sum_{i=0}^{n} a_{i} x_{i}^{t}\right|}{\sum_{i=0}^{n} c_{i}\left|x_{i}^{t}\right|}, & \left(\sum_{i=0}^{n} a_{i} x_{i}^{t}-\sum_{i=0}^{n} c_{i}\left|x_{i}^{t}\right|\right) \leq y^{t} \leq\left(\sum_{i=0}^{n} a_{i} x_{i}^{t}+\sum_{i=0}^{n} c_{i}\left|x_{i}^{t}\right|\right), \\ 0, & \text { otherwise. }\end{cases}
$$

3.3.2. Model Solving. The fuzzy multiple linear regression model could be solved according the following two rules.

Objective. Minimize the sum of spreads of the estimated outputs, which can be represented using an objective function in linear programming (LP) problems as follows:

$$
\min J=\sum_{t=1}^{m} \sum_{i=0}^{n} c_{i}\left|x_{i}^{t}\right|
$$

This approach is called the Linear programming approach in fuzzy regression analysis. The objective function given in (7) is to minimize the total spread of the fuzzy number $\tilde{y}^{t}$.

Constraints. The constraints require that each observation $y^{t}$ has at least $h$ degree of belonging to $\widetilde{y}^{t}$ as $\mu_{\widetilde{y}^{t}}\left(y^{t}\right) \geq h(0 \leq$ $h \leq 1, t=1,2, \ldots, m)$, which is equivalent to

$$
1-\frac{\left|y^{t}-X^{T} a\right|}{c^{T}|X|} \geq h, \quad \forall t=1,2, \ldots, m .
$$

When a fuzzy regression model is established, selecting a proper value for confidence level $h$ is important because it determines the range of possibility in distribution of output $\tilde{y}^{t}$. Depending on whether the decision maker is optimistic or pessimistic about the reliability of data, a higher or lower threshold value can be used. Higher $h$ values can reduce the error and a wider inclusion is obtained.

The analysis above leads to the following linear programming problem, which can be represented as follows:

$$
\begin{aligned}
& \min \quad J=\sum_{t=1}^{m}\left(c_{0}+\sum_{i=1}^{n} c_{i}\left|x_{i}^{t}\right|\right) \\
& \text { s.t. } a_{0}+\sum_{i=1}^{n} a_{i} x_{i}^{t}-(1-h)\left(c_{0}+\sum_{i=1}^{n} c_{i} x_{i}^{t}\right) \leq y^{t}, \\
& t=1,2, \ldots, m, \\
& a_{0}+\sum_{i=1}^{n} a_{i} x_{i}^{t}+(1-h)\left(c_{0}+\sum_{i=1}^{n} c_{i} x_{i}^{t}\right) \geq y^{t}, \\
& t=1,2, \ldots, m, \\
& c_{i} \geq 0, i=1,2, \ldots, n, 0 \leq h \leq 1,
\end{aligned}
$$

where the solution $A_{i}\left(a_{i}, c_{i}\right)$ of function (4) may have 4 states: $a_{i} \neq 0, c_{i}>0 ; a_{i} \neq 0, c_{i}=0 ; a_{i}=0, c_{i}>0 ; a_{i}=0, c_{i}=0$. If $a_{i} \neq 0$, it represents that $Y$ and $x_{i}$ are correlated, and $A_{i}$ is an exact numerical solution when $c_{i}=0$. If $a_{i}=0$, it means that $y^{t}$ and $x_{i}^{t}$ are not relevant, and the corresponding $A_{i}$ could be removed from (1) of the original model.

3.3.3. Deviation Testing and Model Improvement. With those elasticity coefficients calculated under a given confidence level $h$, the correlation equation can be constructed. Then, the deviation spread can be represented as $e^{t}=$ $\left(\max \left(y^{t}\right)-\min \left(y^{t}\right)\right) / 2$. Given an expected deviation range $e_{s}$, if $\max \left(e^{t}\right) \leq e_{s}$, then the model can be recognized as an acceptable solution. Otherwise, the confidence level $h$ needs to be improved for higher precision. The dichotomy method can be used to narrow down the possible interval and get most reasonable solution.

In order to involve the mechanism change resulted from potential time factors, the new results of $X^{t+1}$ and $Y^{t+1}$ will be used for rebuilding the correlation equation model. By this iteration process, the model can have the character of dynamic evolvement and be more representative.

3.4. Service Resource Allocation Optimization Based on the Proposed Model. The results of the FMLR model calculation are forecasted resource real needs and the recommended resource configuration quantity interval $\widetilde{y}^{t}=\left(\bar{y}^{t}, e^{t}\right)$ at the time $t$ of a specific service outlet. The $D$-value between actual available resource AR and recommended interval $\tilde{y}^{t}$ offers a quantitative resource scheduling scheme. If AR is out of the interval, the minimum $D$-value can be recognized as the recommended resource transfer quantity. If $\mathrm{AR}$ is within the interval, there is no need for any change. As those service outlets are not isolated, resources can be shared and transferred between adjacent nodes across the whole service network. In order to reduce those costs caused by long distance resource transfer, service outlets can be grouped and sharing resource within groups is preferred. Only when large fluctuation occurs is cross regional resources allocation allowed. So this needs an integrated and unified management centre for relative factor data collection and resource demand monitoring based on the proposed model. Then, an overall dynamic resource allocation scheme for the service network can be offered.

\section{Case Study}

Company SY is a specialized excavator manufacturer and service provider in Eastern China. In order to extend from 
TABLE 1: Data collection of related factors, resource characters, and primary analysis results of 12 months in 2014 of service agent $S$.

\begin{tabular}{lcccccccccccc}
\hline & Jan & Feb & Mar & Apr & May & Jun & Jul & Aug & Sep & Oct & Nov & Dec \\
\hline QT & 308 & 295 & 357 & 378 & 390 & 415 & 451 & 430 & 471 & 509 & 420 & 363 \\
TE & 3 & 4.2 & 9 & 10 & 12 & 9 & 9 & 8.1 & 13 & 12.5 & 4.2 & 3.6 \\
WI & 0.6 & 0.4 & 0.75 & 0.8 & 0.9 & 0.85 & 0.87 & 0.65 & 0.83 & 0.85 & 0.6 & 0.4 \\
AN & 21 & 20 & 23 & 25 & 26 & 27 & 30 & 29 & 31 & 34 & 28 & 25 \\
AW & 7.24 & 7.60 & 8.35 & 8.64 & 9.23 & 8.30 & 8.27 & 7.72 & 8.77 & 8.24 & 7.14 & 6.72 \\
DN & 19 & 19 & 24 & 27 & 30 & 28 & 31 & 28 & 34 & 35 & 25 & 21 \\
WD & -0.76 & -0.4 & 0.35 & 0.64 & 1.23 & 0.3 & 0.27 & -0.28 & 0.77 & 0.24 & -0.86 & -1.28 \\
\hline
\end{tabular}

QT: quantity of excavators, TE: average worktime per day, WI: average work intensity, AN: actual number of engineers, AW: average work hours of engineers, DN: demand number of engineers, and WD: worktime deviation from standard of service engineers.

traditional manufacturing industry to service based business model, they are building their own product-service systems. Based on its existing supply chain and sales network, Company SY has established a systematic service network covering most parts of the country. By September 2015, the service system has been developed to 38 cooperated agents, over 600 service branches, over 1300 engineering vehicles, and over 2500 service engineers across the country. The company promises to respond to service requests in 15 minutes, arrive in 2 hours, and remove faults within 24 hours.

As the company's service business areas and coverage are expanding rapidly, handling such a complex and huge system while avoiding loss from risks and uncertainties becomes such a challenging task. It is almost impossible to manage so many service resources and respond to high frequency customer requests in a reasonable time all by manual management methods. Advanced information management systems have been applied to support their business transformation.

Site $S$ is one of their core service agents, which offers service for those equipment within $200 \mathrm{~km}$ range. As the frequency and amount of service requests from customers come up randomly, work intensity of service engineers fluctuates a lot, which not only leads to waste of human resources capabilities, but also brings work dissatisfaction to service staffs.

To help the Site $S$ solve the problem, the proposed resource sharing allocation method was applied to the service network optimization. According to the three rules proposed in Section 3.1, three countermeasures are taken as follows.

Measure 1. Along with other 37 cooperated agents, service engineers, engineering vehicles, spare parts, and other materials are shared across districts according to the amount of dynamic service requests (see Figure 6).

Measure 2. Instead of traditional simple rules for human resource allocation by a fixed ratio that each service engineer is responsible for 15 excavators on average dynamic adjustment method with FMLR method is applied to minimize the fluctuation of service resource utilization ratio.

Measure 3. The calculated result of FMLR will offer a reference interval for the planning demand number. Only when the

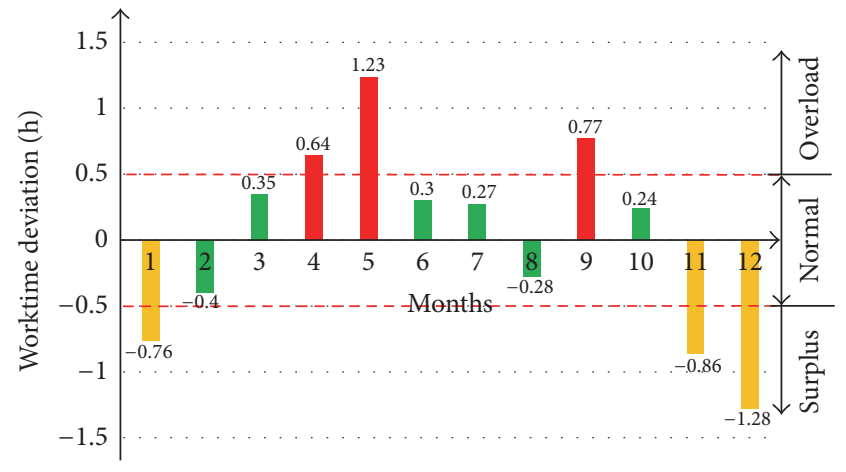

FIGURE 5: Average worktime deviation from standard of service engineers in 2014.

actual number is out of the interval should resources be adjusted to the nearest bound. In this way, those costs caused by unnecessary resource transfer and mobilization can be eliminated to the lowest level.

With the method offered in Section 3.2, apart from the quantity of machines, other related factors also should be considered to construct a more reasonable model. As all kinds of sensors and GPS are installed in every excavator, realtime distribution and working conditions can be monitored. According to a comprehensive analysis integrating expert assessment and historical statistics, another two most relevant factors, including average worktime per day (TE) and average work intensity (WI), are recognized. WI is a ratio between average working load and rated working load, which can be monitored and calculated by the acquired data. As shown in Table 1, those data about related factors influencing service requests and human resource allocation records are collected as the primary analysis database. With the statistics of average work hours of engineers (WI, same to $T_{h}^{t}$ in the reference model), it can be found out obviously that the workload deviation (WD) from standard workhours $T_{s}$ of service engineers, which can be calculated as $\mathrm{WI}-T_{s}=T_{s} \cdot\left(v_{\mathrm{ua}}-1\right)$ according to the method in Section 3.2, fluctuates a lot under the upper and lower limits of $\pm 0.5 h$ (see Figure 5). Only six months in a year made it within anticipated limits. 
TABLE 2: Fuzzy coefficients under different confidence levels.

\begin{tabular}{lcccc}
\hline & $h=0.5$ & $h=0.6$ & $h=0.7$ & $h=0.8$ \\
\hline$\widetilde{A}_{0}$ & $(0,0.05212)$ & $(0,0.4343)$ & $(0,0.3723)$ & $(0,0.3258)$ \\
$\widetilde{A}_{1}$ & $(0.0521,0)$ & $(0.0521,0)$ & $(0.0521,0)$ & $(0.0521,0)$ \\
$\widetilde{A}_{2}$ & $(0.6338,0.1636)$ & $(0.6338,0.1363)$ & $(0.6338,0.1168)$ & $(0.6338,0.1022)$ \\
$\widetilde{A}_{3}$ & $(0.9476,0)$ & $(0.9476,0)$ & $(0.9476,0)$ & $(0.9476,0)$ \\
\hline
\end{tabular}

Using the proposed method, the model function can be written as follows:

$$
\begin{aligned}
\mathrm{DN}^{t}= & \widetilde{A}_{0}+\widetilde{A}_{1} \cdot \mathrm{QT}^{t}+\widetilde{A}_{2} \cdot \mathrm{TE}^{t}+\widetilde{A}_{3} \cdot \mathrm{WI}^{t} \\
= & \left(a_{0}+c_{0}\right)+\left(a_{1}+c_{1}\right) \cdot \mathrm{QT}^{t}+\left(a_{2}+c_{2}\right) \cdot \mathrm{TE}^{t} \\
& +\left(a_{3}+c_{3}\right) \cdot \mathrm{WI}^{t},
\end{aligned}
$$

where, in the equation, $t=1,2, \ldots, 12$. Then, according to (9), the solved model can be written as follows:

$$
\begin{aligned}
\min J= & \sum_{t=1}^{12}\left(c_{0}+c_{1} \mathrm{QT}^{t}+c_{2} \mathrm{TE}^{t}+c_{3} \mathrm{WI}^{t}\right) \\
\text { s.t. } \quad a_{0} & +a_{1} \mathrm{QT}^{t}+a_{2} \mathrm{TE}^{t}+a_{3} \mathrm{WI}^{t} \\
& -(1-h)\left(c_{0}+c_{1} \mathrm{QT}^{t}+c_{2} \mathrm{TE}^{t}+c_{3} \mathrm{WI}^{t}\right) \\
\leq & \mathrm{DN}^{t}, \\
a_{0} & +a_{1} \mathrm{QT}^{t}+a_{2} \mathrm{TE}^{t}+a_{3} \mathrm{WI}^{t} \\
& +(1-h)\left(c_{0}+c_{1} \mathrm{QT}^{t}+c_{2} \mathrm{TE}^{t}+c_{3} \mathrm{WI}^{t}\right) \\
\geq & \mathrm{DN}{ }^{t}, \quad t=1,2, \ldots, 12, c_{1}, c_{2}, c_{3} \geq 0,0 \leq h \leq 1 .
\end{aligned}
$$

MATLAB was implemented to solve the linear programming problem. Given confidence level $h=0.5,0.6,0.7,0.8$, the fuzzy coefficients of the model can be calculated as shown in Table 2.

By testing with the original data in Table 1, it can be found out that all the worktime deviation can be limited within $\pm 0.5 h$ when $h=0.7,0.8$ or above. Here $h=0.7$ is chosen for the final recommend model, based on the consideration of reducing resource transfer workload and cost. So, the correlation equation can be established as follows:

$$
\begin{aligned}
\mathrm{DN}^{t}= & (0,0.3723)+0.0521 \cdot \mathrm{QT}^{t}+(0.6338,0.1168) \\
& \cdot \mathrm{TE}^{t}+0.9476 \cdot \mathrm{WI}^{t} .
\end{aligned}
$$

Then, the model was applied to the adjustment of service engineer allocation in the following 9 months in 2015 for model validation and verification. As shown in Table 3, with equation (12) and those data of QT, TE, and WI got from January to September, recommended allocation schemes of $\mathrm{DN}$ are provided, which are those integers between the up boundary $\mathrm{DN}+$ and the low boundary $\mathrm{DN}-$. AN is the actual configuration results and RT is service engineer transfer number with adjacent service agents in every month.

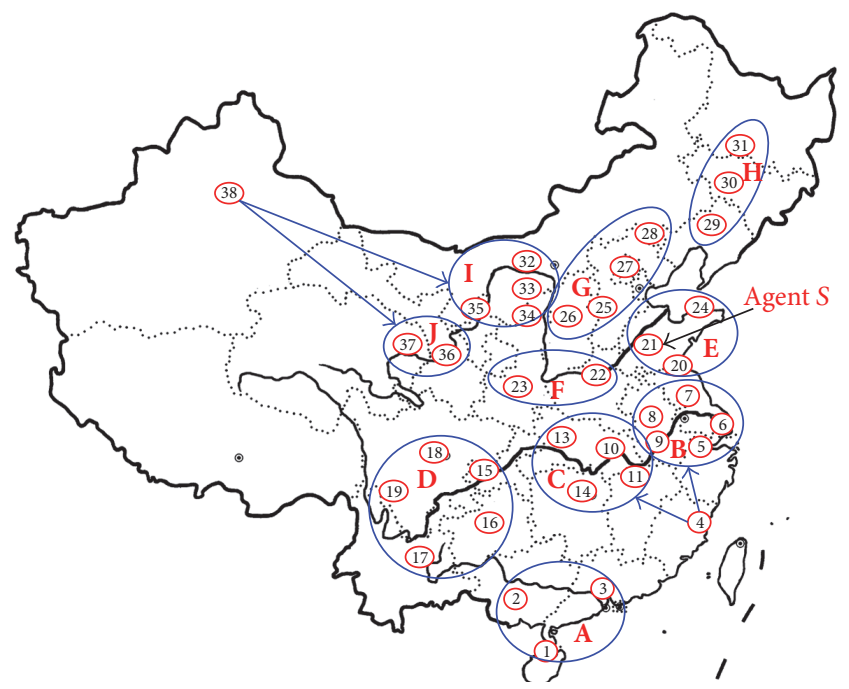

FIGURE 6: Distribution and grouping of service agents across the country.

The full view distribution of 38 service agents of company SY is depicted in Figure 6. Service engineer demands of every single service agent can be predicted using the proposed model. The factors and coefficient may differ from each other. Based on existing service network of company SY, those service agents are divided into 10 groups according to the results of cost-efficient optimization based on density clustering and NSGA-II, which is not the main discussion of this article. According to Measure 1, by grouping three or more adjacent service agents together, whether surplus or overload, human resource can be basically balanced by personnel exchange within group, or by adjustment across groups. As shown in Figure 6, Agent $S$ is numbered 21 and grouped with another two service agents, Number 20 and 24. As depicted in Table 3 and Figure 7, after optimization using the proposed model, the spread of worktime deviation of Agent $S$ has almost been controlled within anticipated $\pm 0.5 \mathrm{~h}$. Only one special case in the past nine months occurred.

\section{Discussion and Conclusions}

The randomness and fluctuation of service requests from customers lead to the volatility of IPS2 resource utilization ratio. Excessive volatility causes the problem that resources are either overloaded or surplus in use, especially for human resources. In order to bridge the gap between the existing problem and insufficient researches, based on previous research on IPS2 and related resource allocation optimization 
TABLE 3: Data collection for verification and optimization results in 2015 of Agent $S$.

\begin{tabular}{|c|c|c|c|c|c|c|c|c|c|}
\hline & Jan & Feb & Mar & Apr & May & Jun & $\mathrm{Jul}$ & Aug & Sep \\
\hline QT & 313 & 345 & 395 & 463 & 450 & 410 & 451 & 430 & 468 \\
\hline $\mathrm{TE}$ & 4 & 4.5 & 7 & 12 & 13 & 9 & 9 & 9 & 12 \\
\hline WI & 0.6 & 0.4 & 0.75 & 0.8 & 0.9 & 0.85 & 0.8 & 0.6 & 0.82 \\
\hline $\mathrm{DN}+$ & 20.25 & 22.10 & 26.91 & 34.26 & 34.43 & 29.29 & 31.38 & 30.09 & 34.54 \\
\hline DN- & 19.41 & 21.21 & 25.73 & 32.49 & 32.54 & 27.87 & 29.96 & 28.68 & 32.77 \\
\hline AN & 20 & 22 & 26 & 32 & 33 & 29 & 30 & 30 & 33 \\
\hline RT & -1 & +2 & +4 & +6 & +1 & -3 & +1 & - & +3 \\
\hline AW & 7.6 & 7.8 & 8.13 & 8.4 & 8.6 & 7.7 & 8.34 & 7.72 & 8.45 \\
\hline WD & -0.4 & -0.2 & 0.13 & 0.4 & 0.6 & -0.3 & 0.34 & -0.28 & 0.45 \\
\hline
\end{tabular}

RT: Human Resource transfer quantity. Others can be found below Table 1.

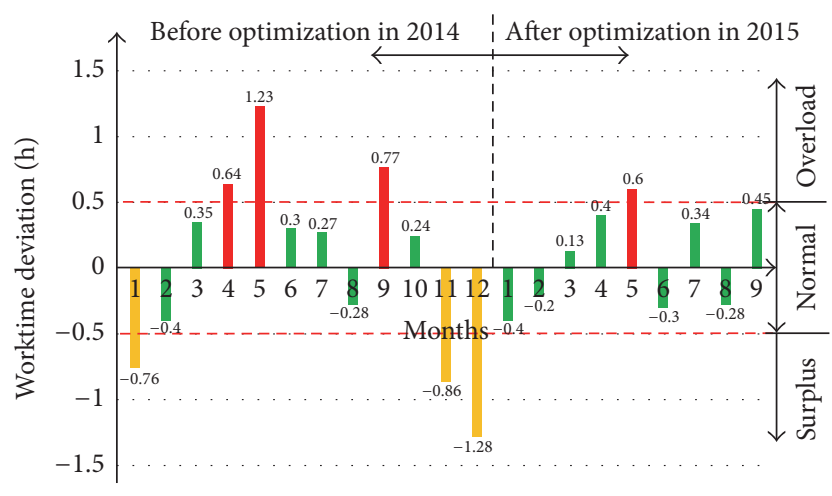

FIGURE 7: Comparison of average workhour deviation before and after the resource allocation optimization of Agent $S$.

methods, more targeted and in-depth work has been developed in this article. Main innovative contributions of this work include the following:

(i) The mechanisms of IP2 resource utilization rate fluctuation are analysed in detail and spotted accurately from the views of both quantity and quality.

(ii) Three basic rules and the technology roadmap are developed for industrial product-service resource allocation optimization.

(iii) A method based on fuzzy multiple linear regression is put forward in this work for resource actual demands forecasting and IPS2 resource supplying and allocation balance.

The method is tested and verified by the case study of human resource allocation optimization for construction machinery service system in some local areas of China, which is proved reasonable and feasible. The calculation of actual resource demands and utilization ratio fluctuation by historical data statistics and conversion is simple and practical. The method of improved FMLR keeps the advantage of visualizing correlation coefficients between factors and optimization objects. Meanwhile, the integration of fuzzy theory keeps the coefficients in a reasonable range, which helps decision making that resources are transferred only when incremental quantity is out of the range, which can effectively reduce costs caused by resource reallocation while balance resource utilization ratio fluctuation is within an acceptable interval.

However, there is still scope for further improvement. The scenario of multitypes of resource allocation network leads to more complex forecasting model and optimization algorithms, which will be our following research focus. Meanwhile, a specialized IPS2 resource allocation optimization supporting software based on the proposed method could be developed and integrated into enterprise information decision systems, offering speed computing abilities for large scale data of multiple resource items and complex service network. IPS2 is a sustainable business model grown out of sharing economy. Continuous research will benefit the business ecosystem a lot in more aspects and in greater depth.

\section{Competing Interests}

The authors declare that there is no conflict of interests regarding the publication of this paper.

\section{Acknowledgments}

The authors would like to thank Shanghai Institute of Producer Service Development (SIPSD) and Shanghai Research Centre for Industrial Informatics $\left(\mathrm{SRCI}^{2}\right)$ for the funding support to this research.

\section{References}

[1] O. K. Mont, "Clarifying the concept of product-service system," Journal of Cleaner Production, vol. 10, no. 3, pp. 237-245, 2002.

[2] R. F. Lusch, "Service-dominant logic: reactions, reflections and refinements," Marketing Theory, vol. 6, no. 3, pp. 281-288, 2006.

[3] L. Krucken and A. Meroni, "Building stakeholder networks to develop and deliver product-service-systems: practical experiences on elaborating pro-active materials for communication," Journal of Cleaner Production, vol. 14, no. 17, pp. 1502-1508, 2006.

[4] C. Dance and A. A. Gaivoronski, "Stochastic optimization for real time service capacity allocation under random service demand," Annals of Operations Research, vol. 193, pp. 221-253, 2012. 
[5] O. Mont, "Product-service systems," Final Report, IIIEE, Lund University, 2000.

[6] J. C. Aurich, C. Fuchs, and C. Wagenknecht, "Life cycle oriented design of technical product-service systems," Journal of Cleaner Production, vol. 14, no. 17, pp. 1480-1494, 2006.

[7] H. Meier, R. Roy, and G. Seliger, "Industrial product-service systems-IPS2," CIRP Annals-Manufacturing Technology, vol. 59, no. 2, pp. 607-627, 2010.

[8] A. Tukker, "Eight types of product-service system: eight ways to sustainability? Experiences from SusProNet," Business Strategy and the Environment, vol. 13, no. 4, pp. 246-260, 2004.

[9] P. P. Wang, X. G. Ming, D. Li, F. B. Kong, L. Wang, and Z. Y. $\mathrm{Wu}$, "Status review and research strategies on product-service systems," International Journal of Production Research, vol. 49, no. 22, pp. 6863-6883, 2011.

[10] J. Aurich, E. Schweitzer, and C. Fuchs, "Life cycle management of industrial product-service systems," in Advances in Life Cycle Engineering for Sustainable Manufacturing Businesses, pp. 171176, Springer, London, UK, 2007.

[11] T. S. Baines, H. W. Lightfoot, S. Evans et al., "State-of-the-art in product-service systems," Proceedings of the Institution of Mechanical Engineers, Part B: Journal of Engineering Manufacture, vol. 221, no. 10, pp. 1543-1552, 2007.

[12] E. Sundin, G. Ölundh Sandström, M. Lindahl, A. Öhrwall Rönnbäck, T. Sakao, and T. C. Larsson, "Challenges for Industrial Product/Service Systems: experiences from a learning network of large companies," in Proceedings of the 1st CIRP Industrial Product/Service Systems Conference, pp. 298-304, Cranfield, UK, April 2009.

[13] G. V. A. Vasantha, R. Roy, A. Lelah, and D. Brissaud, "A review of product-service systems design methodologies," Journal of Engineering Design, vol. 23, no. 9, pp. 635-659, 2012.

[14] N. Maussang, P. Zwolinski, and D. Brissaud, "Product-service system design methodology: from the PSS architecture design to the products specifications," Journal of Engineering Design, vol. 20, no. 4, pp. 349-366, 2009.

[15] H. Meier and B. Funke, "Resource planning of industrial product-service systems (IPS ${ }^{2}$ ) by a heuristic resource planning approach," in Proceedings of the 2nd CIRP Industrial Product/Service Systems Conference, pp. 339-346, Linköping, Sweden, April 2010.

[16] G. Schuh, M. Hübbers, G. Gudergan, and F. Director, "Structural model of resources in product service systems-a prerequisite to portfolio design and planning," in Proceedings of the 2nd CIRP Industrial Product/Service Systems Conference, pp. 317-322, Linköping, Sweden, April 2010.

[17] M. Steven and A. Richter, "Hierarchical planning for industrial product service systems," in Proceedings of the CIRP Industrial Product/Service Systems Conference, pp. 151-158, Linköping, Sweden, April 2010.

[18] H. Meier and O. Völker, "Industrial product-service-systemstypology of service supply chain for IPS2 providing," in Manufacturing Systems and Technologies for the New Frontier, pp. 485488, Springer, London, UK, 2008.

[19] J. A. Erkoyuncu, R. Roy, E. Shehab, and K. Cheruvu, "Understanding service uncertainties in industrial product-service system cost estimation," International Journal of Advanced Manufacturing Technology, vol. 52, no. 9-12, pp. 1223-1238, 2011.

[20] M. Rese, M. Karger, and W.-C. Strotmann, "The dynamics of industrial product service systems (IPS2) - using the net present value approach and real options approach to improve life cycle management," CIRP Journal of Manufacturing Science and Technology, vol. 1, no. 4, pp. 279-286, 2009.

[21] S. Rehman, "Long-term wind speed analysis and detection of its trends using Mann-Kendall test and linear regression method," Arabian Journal for Science and Engineering, vol. 38, no. 2, pp. 421-437, 2013.

[22] I. Ladlani, L. Houichi, L. Djemili, S. Heddam, and K. Belouz, "Estimation of daily reference evapotranspiration (ET0) in the North of Algeria using adaptive neuro-fuzzy inference system (ANFIS) and multiple linear regression (MLR) models: a comparative study," Arabian Journal for Science and Engineering, vol. 39, no. 8, pp. 5959-5969, 2014.

[23] H. Tanaka, "Linear regression analysis with fuzzy model," IEEE Transactions on Systems, Man, and Cybernetics, vol. 12, no. 6, pp. 903-907, 1982.

[24] L. Abdullah and N. Zamri, "Road traffic accidents models using threshold levels of fuzzy linear regression," in Proceedings of the International Conference on Statistics in Science, Business, and Engineering (ICSSBE '12), pp. 1-5, September 2012.

[25] Z. Ramedani, M. Omid, A. Keyhani, B. Khoshnevisan, and H. Saboohi, "A comparative study between fuzzy linear regression and support vector regression for global solar radiation prediction in Iran," Solar Energy, vol. 109, no. 1, pp. 135-143, 2014.

[26] K. D. Atalay, E. Eraslan, and M. O. Çinar, "A hybrid algorithm based on fuzzy linear regression analysis by quadratic programming for time estimation: an experimental study in manufacturing industry," Journal of Manufacturing Systems, vol. 36, pp. 182-188, 2015. 


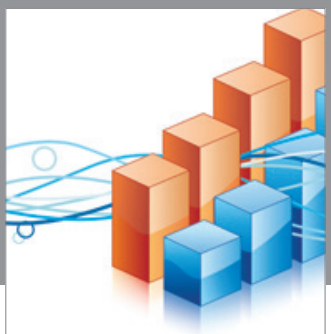

Advances in

Operations Research

vatem alat4

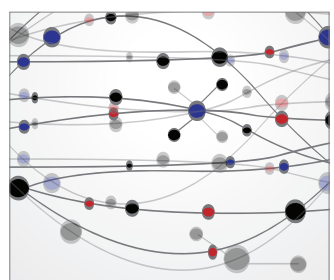

\section{The Scientific} World Journal
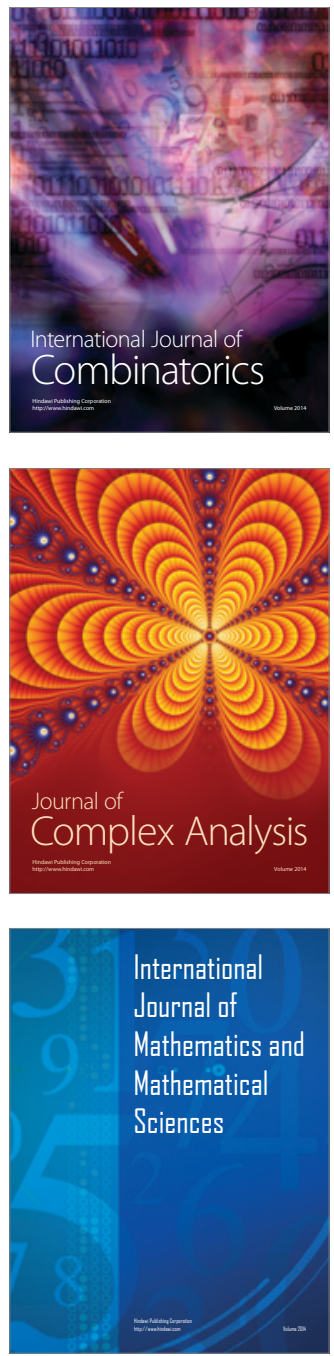
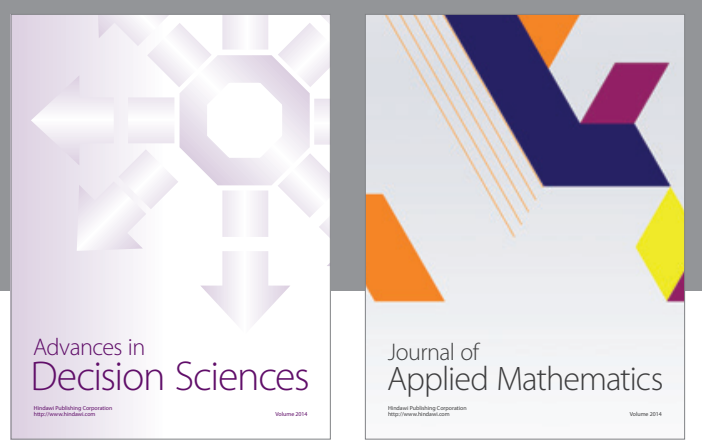

Algebra

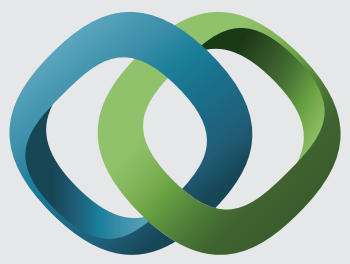

\section{Hindawi}

Submit your manuscripts at

https://www.hindawi.com
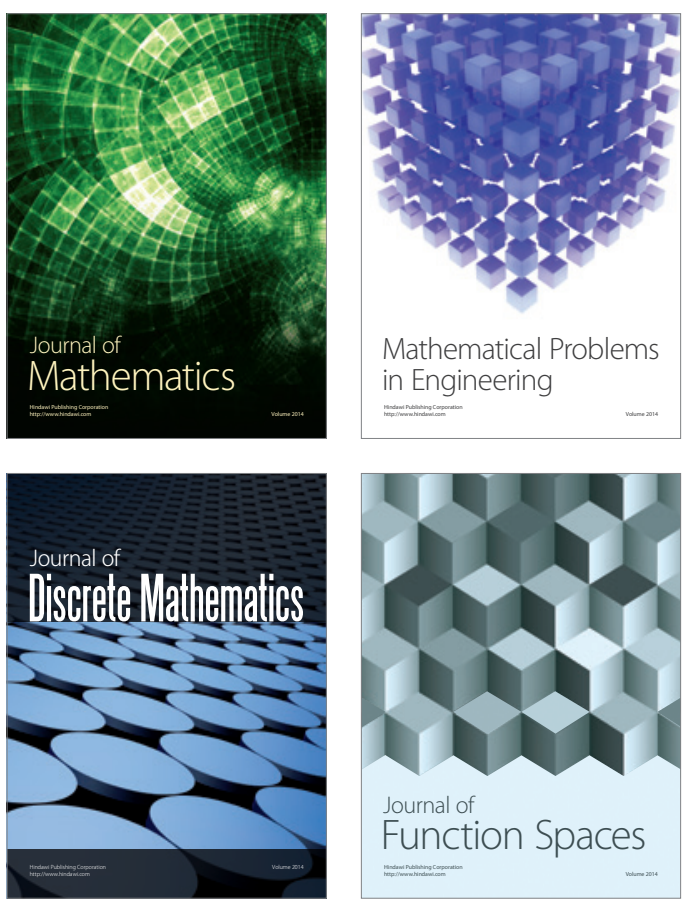

Mathematical Problems in Engineering
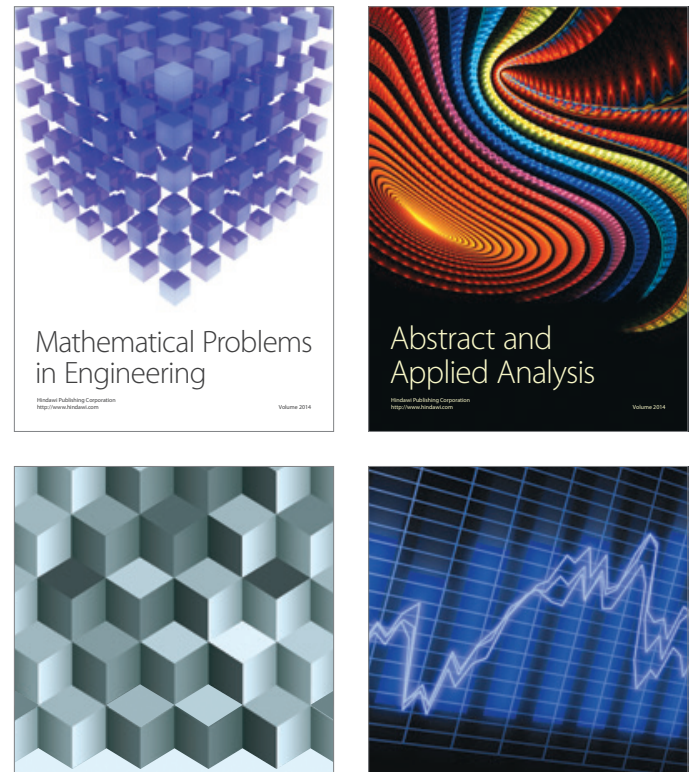

Journal of

Function Spaces

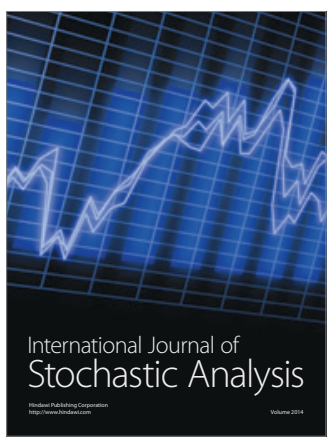

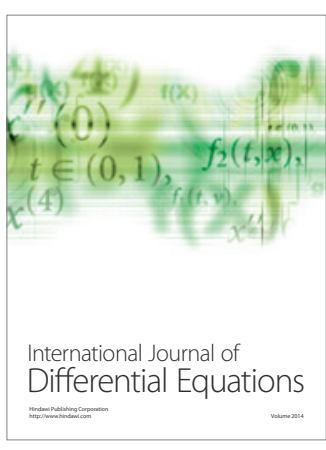
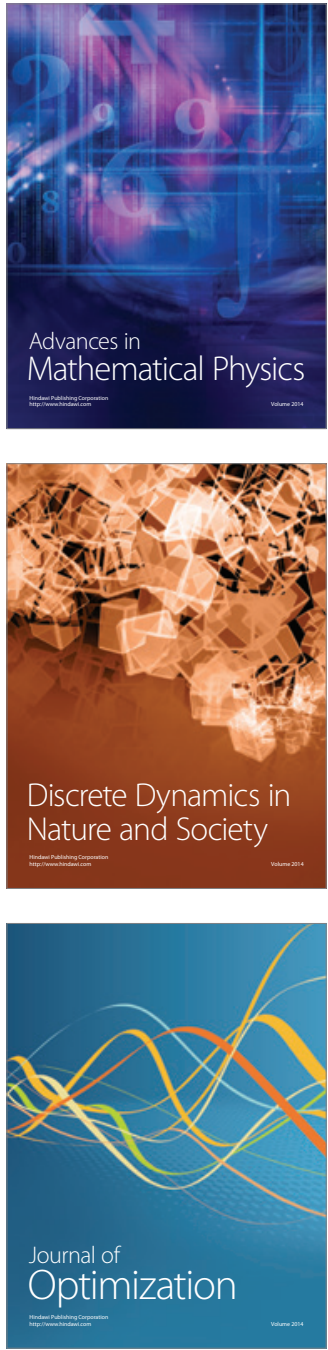